\title{
Nature-Based Solutions: Traditional Approaches Complying with Nowadays Engineering and Ecosystem-Related Challenges
}

\author{
Michael Obriejetan* and Rosemarie Stangl \\ Institute of Soil Bioengineering and Landscape Construction (IBLB), University of Natural Resources and Life Sciences, Vienna (BOKU)
}

*Corresponding author: Michael Obriejetan, Institute of Soil Bioengineering and Landscape Construction (IBLB), University of Natural Resources and Life Sciences, Vienna (BOKU), Peter-Jordan-Straße 82/III, 1190 Wien, Austria.

Received Date: November 15, 2019

Published Date: November 19, 2019

\begin{abstract}
In light of the ongoing climate and biodiversity debates, nature-based solutions have become key to restore lost ecosystems related to civil and water engineering activities. Hitherto, Soil and Water Bioengineering (SWB) designs have been playing subordinate roles in engineering applications due to little recognition from a (geo)technical point of view and to widespread limited trust and conviction in long-lasting safety and predictability. For decades SWB techniques have been primarily used for stabilization and mechanical reinforcement of slopes, riverbanks and roadside infrastructures. However, SWB offers a variety of designs and applications complying inherently with the core targets of Naturebased Solutions (NbS). SWB systems advance great potential and are increasingly acknowledged for playing a key role in ecological and structural restoration projects, in hazard risk mitigation and in land management providing manifold functionalities. They deliver important services to storm water and runoff retention, landscape and habitat connectivity, and to climate change adaptation.
\end{abstract}

Keywords: Soil and water bioengineering; Nature-based solutions (NbS); Habitat establishment; Erosion control; Slope stabilization; Ecosystem services

Abbreviations: • SWB - Soil and water Bioengineering

- $\quad \mathrm{NbS}$ - Nature-based Solutions

\section{Introduction}

The degradation of ecosystems, their services and natural resources during the past decades poses a major current and future challenge against the backdrop of climate and global changes, and is currently creating a set of new tasks and requirements in civil and water engineering In order to maintain and re-establish near natural ecosystems, multiple perspectives such as ecology, economy and sociology are to be included in planning and decision-making processes in engineering projects for ecosystem enhancement and design improvement. Strengthening and restoring sustainable ecosystems using an integral approach is key in the traditional understanding of SWB, defined as "discipline that combines technology and biology, making use of plants and plant communities to help protect land uses and infrastructures, and contribute to landscape development" [1]. SWB approaches use plants for engineering purposes, and consequently pose a holistic and interdisciplinary methodology for strategic and operational planning and implementation of Nature-based Solutions (NbS) in the field of infrastructure design and management [2]. SWB is combining innovative technical solutions as well as traditional ecologically sound restoration techniques. This essentially serves sustainable $\mathrm{NbS}$ implementation helping to increase ecosystem service capacity by simultaneously maintaining structural and technical safety [3]. The positive effects of vegetation on the stability of slopes and embankments has been known for many centuries and has since been consciously used for erosion protection measures. The main stability-enhancing aspects of vegetation are, among others: 1) covering the (bare) soil protecting the slope against surface-near water and wind erosion, 2) reinforcement of the soil body due to plant inlays and subsequent root development resulting in increased shear strength and soil cohesion (root 
cohesion). The graphic below (Figure 1) shows a systematic system overview of the main aspects to be considered for an integral technical-biological approach in the field of slope protection and erosion control.

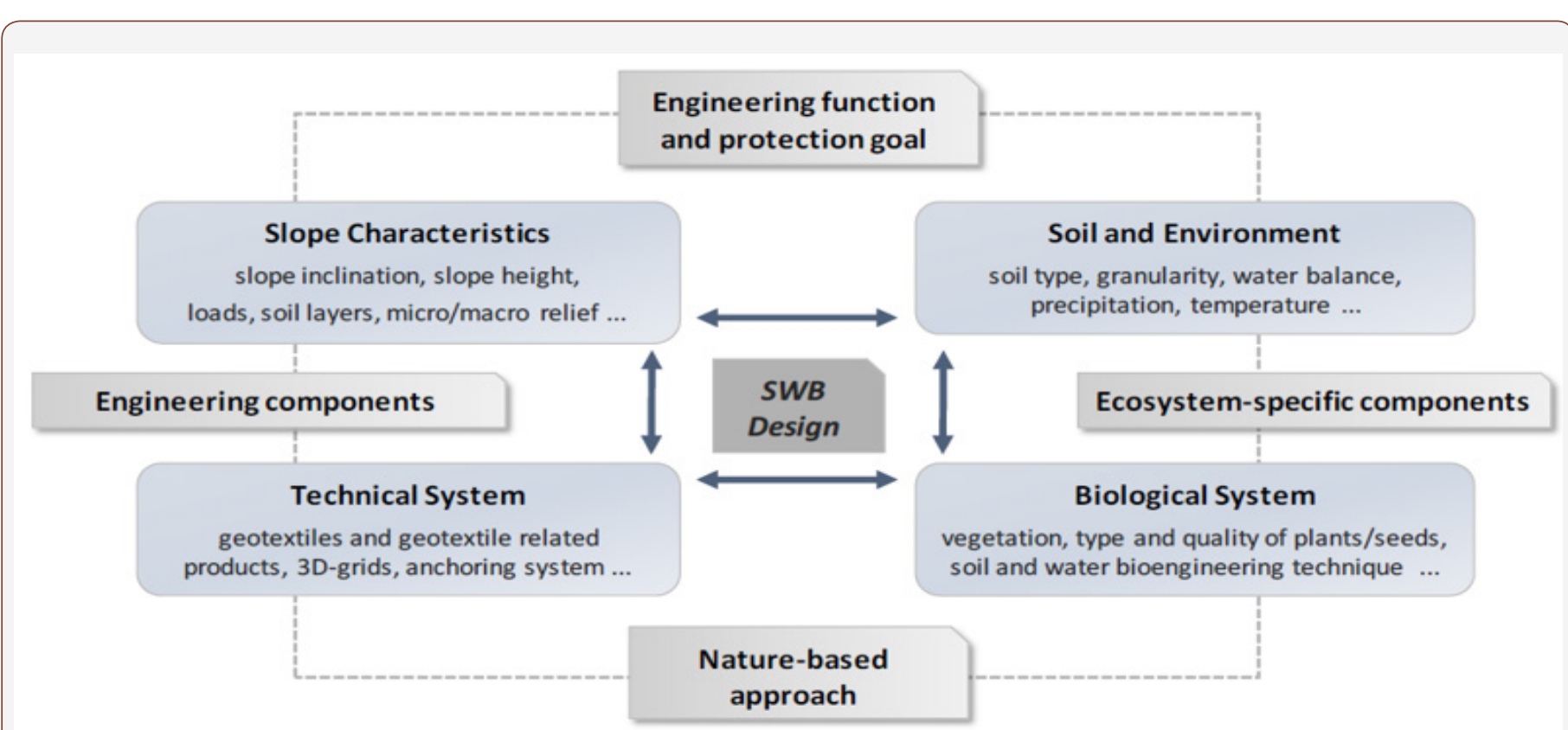

Figure 1: Nature-based approach in civil and water engineering by cross linking SWB principles.

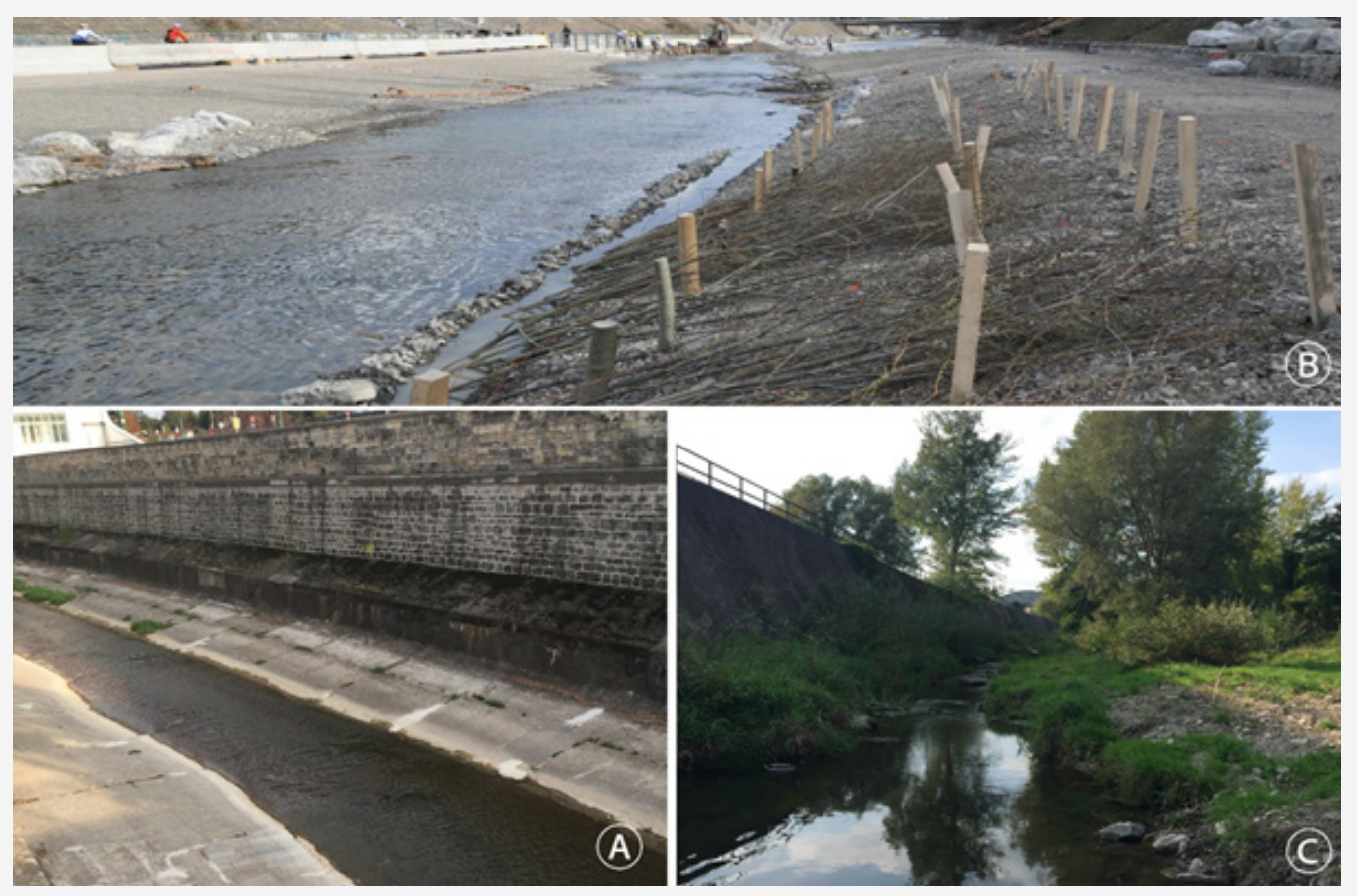

Figure 2: Restoration of sealed surfaces and nature-based engineering solutions using SWB techniques. A) concrete riverbed - situation before restoration works, B) willow brush mattress during construction, C) near-natural state after the restoration works (implementation in Vienna, Austria 2014)

A specific case of application stepped into the limelight regarding the requirements of the EU Water Framework Directive, aiming at good water quality and availability with particular emphasis on interlinked aquatic and terrestrial ecosystems [4]. Currently, a large number of confined and structurally reinforced watercourses, channels and reservoirs have achieved a stage of functional impairment and increasing demand for restoration, maintenance and repair. This will lead to higher efforts for the realization of combined geotechnically reliable but also naturebased solutions. Figure 2 illustrates the process of restoring destroyed river environments from a completely sealed status to a near natural condition. SWB implementation follows a clear codex of structural and engineering principles [1]. In order to ensure functional capacity immediately after installation, integrated construction concepts and measures require the use of technical components as well as living construction material. When planned 
and applied correctly they withstand the expected forces and mechanical loads undamaged (e.g. shear stress, hydraulic loads, turbulences). The underlying mechanism of plants to stabilize and protect slopes, banks of all sorts of water bodies and open soil surfaces from erosion follows a dual mode of bio-mechanical logic by (a) below ground rooting and reinforcing loose substrates and (b) by covering bare soil surfaces and intercepting atmospheric stresses through above ground biomass. This results in an improvement of resilience during stress periods (floods, heat etc) and, at the same time, an increase in ecosystem service capacity with particular focus on biodiversity, ecosystem connectivity and environmental quality.

Combining innovative (geo)technical solutions with traditional, ecologically sound restoration techniques opens new opportunities for the development and realization of resilient and long-term stable protection systems for diverse fields of engineering applications. Up-to-date scientific knowledge on bio-mechanical effects and processes due to vegetation cover and plant roots helps to find adequate solutions meeting geotechnical requirements as well as ecological and economic benefits. However, clearing old prejudices towards plant based SWB and NbS applications is key to fulfil and maximize their potentials in a new era of challenges.

\section{Acknowledgement}

None.

\section{Conflict of Interest}

No conflict of interest.

\section{References}

1. EFIB (2015) European Guidelines for Soil and Water bioengineering. European Federation for Soil and Water Bioengineering (Editor).

2. Fernandes J, Guiomar N (2018) Nature-based solutions: The need to increase the knowledge on their potentialities and limits. Land Degrad Dev 29(6): 1925-1939.

3. Hoerbinger S, Immitzer M, Obriejetan M, Rauch HP (2018) GISbased assessment of ecosystem service demand concerning green infrastructure line-side vegetation. Ecol Eng 121: 114-123.

4. European Commission (2000) Directive 2000/60/EC of the European Parliament and of the Council of 23 October 2000 establishing a framework for community action in the field of water policy. Brussels. 